\title{
Intermittent Fasting (Alternate Day Fasting) in Healthy, Non-obese Adults: Protocol for a Cohort Trial with an Embedded Randomized Controlled Pilot Trial
}

\author{
Norbert J. Tripolt · Slaven Stekovic · Felix Aberer · Jasmin Url • Peter N. Pferschy · Sabrina Schröder • \\ Nicolas Verheyen · Albrecht Schmidt · Ewald Kolesnik · Sophie H. Narath • Regina Riedl • \\ Barbara Obermayer-Pietsch · Thomas R. Pieber · Frank Madeo · Harald Sourij
}

Received: May 17, 2018 / Published online: July 25, 2018

(C) The Author(s) 2018

\section{ABSTRACT}

Background/objectives: Alternate day fasting (ADF) is a subtype of intermittent fasting and is defined as a continuous sequence of a fast day (100\% energy restriction, zero calories) and a feed day (ad libitum food consumption), resulting in roughly 36 -h fasting periods. Previous studies demonstrated weight reductions and improvements of cardiovascular risk factors with ADF in obese subjects. However, rigorous data on potential endocrine, metabolic and

Norbert J. Tripolt and Slaven Stekovic have contributed equally to this work.

Enhanced digital features To view enhanced digital features for this article go to https://doi.org/10.6084/ m9.figshare.6683597.

N. J. Tripolt · F. Aberer · J. Url · P. N. Pferschy ·

B. Obermayer-Pietsch - T. R. Pieber · H. Sourij ( $\square)$

Division of Endocrinology and Diabetology,

Department of Internal Medicine, Medical

University of Graz, Graz, Austria

e-mail: ha.sourij@medunigraz.at

S. Stekovic · S. Schröder · F. Madeo ( $₫)$

Institute of Molecular Biosciences, University of Graz, Graz, Austria

e-mail: frank.madeo@uni-graz.at

J. Url · P. N. Pferschy · S. H. Narath .

B. Obermayer-Pietsch · T. R. Pieber · H. Sourij

Center for Biomarker Research in Medicine, CBMed,

Graz, Austria cardiovascular effects, besides weight loss, are lacking. Therefore we aim to investigate the short- and mid- to long-term clinical and molecular effects of ADF in healthy non-obese subjects.

Methods: We will perform a prospective cohort study with an embedded randomized controlled trial (RCT) including 90 healthy subjects. Thirty of them will have performed ADF for at least 6 months (mid-term group). Sixty healthy subjects without a particular diet before enrolment will serve as the control group. These subjects will be 1:1 randomized to either continuing their current diet or performing ADF for 4 weeks. All subjects will undergo study procedures that will be repeated in RCT participants after 4 weeks. These procedures will include assessment of outcome parameters, dual-energy X-ray absorptiometry, measurement of

N. Verheyen · A. Schmidt · E. Kolesnik

Division of Cardiology, Department of Internal

Medicine, Medical University of Graz, Graz, Austria

R. Riedl

Institute for Medical Informatics, Statistics and Documentation, Medical University of Graz, Graz, Austria

F. Madeo

BioTechMed Graz, Graz, Austria 
endothelial function, an oral glucose tolerance test, 24-h blood pressure measurement, retinal vessel analysis, echocardiography and physical activity measurement by an accelerometer. Blood, sputum, buccal mucosa and faeces will be collected for laboratory analyses. Participants in the RCT will wear a continuous glucose monitor to verify adherence to the study intervention.

Planned outcomes: The aim of this project is to investigate the effects of ADF on human physiology and molecular cellular processes. This investigation should gain in-depth mechanistic insights into the concept of ADF and form the basis for larger subsequent cohort recruitment and consecutive intervention studies.

Trial registration: NCT02673515; registered 24 November 2015. Current protocol date/version: 7 February 2017/version 1.8.

Keywords: Alternate day fasting; Blood pressure; Cell death; Cell signalling; Cohort study; Endothelial function; Glucose metabolism; Healthy subjects; Insulin sensitivity; Intermittent fasting

\section{INTRODUCTION}

\section{Background}

Intermittent fasting, alternate day fasting (ADF) and further forms of periodic caloric restriction are not really methods of energy deprivation, because-at least theoretically-persons could eat double on the second day. Intermittent fasting in heterogeneous forms has been practiced for religious and health reasons for hundreds of years [1]. ADF regimens are defined as 'feast days' on which food is consumed ad libitum, which alternate with 'fast days' on which food is withheld or reduced. The feast and fast periods are typically $24 \mathrm{~h}$ each, but may vary [4]. This is the most frequently used protocol for intermittent fasting studies in mice and rats [2]. In everyday life, this protocol is often modified to allow a small caloric intake (e.g. about $25 \%$ of the individual's energy needs).
Over the past decade, ADF has gained great popularity in a weight management context [3-5], leading to a widely used lifestyle trend that is said to have effects on general health status and prolongation of life expectancy. However, scientific evidence for the effects of ADF in humans is rare and metabolic data are often extrapolated from animal studies only.

Several trials found beneficial metabolic and cardiovascular effects, such as reduced circulating glucose concentrations [6-8] as well as reductions in heart rate or blood pressure [9] and cholesterol or triglyceride concentrations [10] after 8-24 weeks of ADF in rodents.

Additionally, a study in which mice were allocated to either intermittent fasting with a high-fat diet in the feeding periods or regularly feeding with isocaloric, carbohydrate and fat intake in both groups demonstrated that ADF was associated with prevention of obesity, hyperinsulinaemia, hepatic steatosis and inflammation [11].

Besides caloric restriction and effects on established cardiovascular risk factors, intermittent fasting seems to activate cell autophagy processes that increase cellular stress resistance and remove accumulated molecules and organelles that can lead to various pathologies [12-14]. Further research suggested a life-prolonging effect of ADF in rodents [15-17].

Findings from ADF studies in humans showed significant weight reductions [18-23], reduction in waist-to-hip ratio [18, 20-22, 24], fat mass [18, 20-23, 25-27] and also fat-free mass [22, 25-27]. Also the effects seen in the animal studies on cardiovascular risk factors, such as reductions in triglycerides [28-31], lowdensity lipoprotein (LDL) cholesterol [28-30] and systolic blood pressure [30] and increases in LDL particle size $[21,32,33]$ and high-density lipoprotein (HDL) cholesterol [21, 28, 31] were observed. Many studies [18, 21-23, 25, $27,28,34]$ showed no change in fasting glucose levels, though some of these trials $[21,22,25,27]$ reported a decrease in fasting circulating insulin concentrations.

A major limitation of the majority of these trials [35] is that they either compared the effectiveness of intermittent fasting with continuous energy restriction without a 
Table 1 Visit overview

\begin{tabular}{|c|c|c|c|c|c|}
\hline \multicolumn{6}{|l|}{ Randomized Controlled Trial } \\
\hline \multirow[t]{3}{*}{ RCT } & \multicolumn{5}{|c|}{ Study period } \\
\hline & Baseline & & Visit & & Follow-up \\
\hline & (Visit 1) & 2 & 3 & 4 & (Visit 5) \\
\hline Time point & 0 & $\begin{array}{c}9 \text { days } \pm \\
4 \text { days } \\
\text { after } \\
\text { baseline }\end{array}$ & $\begin{array}{c}21 \text { days } \pm 2 \\
\text { days after } \\
\text { visit } 2\end{array}$ & $\begin{array}{c}7 \text { days } \pm 2 \\
\text { days after } \\
\text { visit } 3\end{array}$ & $\begin{array}{c}2 \text { years after } \\
\text { visit } 3\end{array}$ \\
\hline \multicolumn{6}{|l|}{ Enrolment } \\
\hline Eligibility screen & $\mathrm{x}$ & & & & \\
\hline Informed consent & $\mathrm{x}$ & & & & \\
\hline Randomization & & $\mathrm{x}$ & & & \\
\hline Allocation & $\mathrm{x}$ & & & & \\
\hline \multicolumn{6}{|l|}{ Interventions } \\
\hline \multicolumn{6}{|l|}{ Alternate Day Fasting (ADF rand.) } \\
\hline \multicolumn{6}{|l|}{ Ingestion ad libitum (Controls) } \\
\hline \multicolumn{6}{|l|}{ Assessments } \\
\hline \multicolumn{6}{|l|}{ CRF } \\
\hline Demographic data & $\mathrm{x}$ & & & & \\
\hline Anthropometric measurements & $x$ & & & & $x$ \\
\hline Vital signs (Blood pressure, heart rate) & $x$ & $\mathrm{x}$ & & $x$ & $\mathrm{x}$ \\
\hline Medical History & $x$ & & & & $x$ \\
\hline Concomitant medication & $\mathrm{x}$ & $x$ & & $x$ & $x$ \\
\hline Physical examination & $\mathrm{x}$ & & & & $x$ \\
\hline \multicolumn{6}{|l|}{ Laboratory } \\
\hline Oral glucose tolerance test (OGTT) & & $x$ & & $\mathrm{x}$ & \\
\hline Saliva sampling & & $\mathrm{x}$ & & $\mathrm{x}$ & \\
\hline Urine pregnancy test (females) & & $\mathrm{x}$ & & $\mathrm{x}$ & \\
\hline Buccal mucosa sampling & & $\mathrm{x}$ & & $\mathrm{x}$ & \\
\hline
\end{tabular}


Table 1 continued

\begin{tabular}{|c|c|c|c|c|c|}
\hline $\begin{array}{l}\text { Laboratory measurements including } \\
\text { routine safety lab }\end{array}$ & & $\mathrm{x}$ & & $\mathrm{x}$ & $\mathrm{x}$ \\
\hline Urine sampling & & $\mathrm{x}$ & & $\mathrm{x}$ & \\
\hline Faeces sampling & & $\mathrm{x}$ & & $\mathrm{x}$ & \\
\hline \multicolumn{6}{|l|}{ Issue of devices } \\
\hline $\begin{array}{l}24 \mathrm{~h} \text { ambulatory blood pressure } \\
\text { monitoring }\end{array}$ & $\mathrm{x}$ & & $\mathrm{x}$ & & \\
\hline Physical activity measurement & $\mathrm{X}$ & & $\mathrm{X}$ & & \\
\hline Continuous glucose monitoring & $\mathrm{x}$ & & $\begin{array}{l}\text { X (ADF } \\
\text { only) }\end{array}$ & & \\
\hline $\begin{array}{l}\text { Glucometer for calibration of glucose } \\
\text { monitoring }\end{array}$ & $\mathrm{x}$ & & $\mathrm{x}$ & & \\
\hline \multicolumn{6}{|l|}{ Investigations } \\
\hline Endothelial function (EndoPAT) & & $\mathrm{x}$ & & $\mathrm{x}$ & \\
\hline $\begin{array}{l}\text { Bone densitometry and body } \\
\text { composition (Dual-energy X-ray } \\
\text { absorptiometry) }\end{array}$ & & $\mathrm{x}$ & & $\mathrm{x}$ & \\
\hline Hand grip test & & $\mathrm{X}$ & & $\mathrm{X}$ & \\
\hline Echocardiogram & & $\mathrm{X}$ & & $\mathrm{X}$ & \\
\hline Electrocardiogram (ECG) & & $\mathrm{X}$ & & $\mathrm{X}$ & \\
\hline Retina vessel analysis & & $\mathrm{X}$ & & $\mathrm{X}$ & \\
\hline Resting energy expenditure (REE) & & $\mathrm{X}$ & & $\mathrm{X}$ & \\
\hline \multicolumn{6}{|l|}{ Questionnaires } \\
\hline Food frequency questionnaire (FFQ) & & $\mathrm{x}$ & & $\mathrm{x}$ & $\mathrm{x}$ \\
\hline $\begin{array}{l}\text { International physical activity } \\
\text { questionnaire (IPAQ) }\end{array}$ & & $\mathrm{x}$ & & $\mathrm{x}$ & $\mathrm{x}$ \\
\hline Health survey short form (SF36) & & $\mathrm{X}$ & & $\mathrm{X}$ & $\mathrm{x}$ \\
\hline
\end{tabular}

\begin{tabular}{|l|c|c|c|}
\hline \multicolumn{2}{|c|}{ Cohort study } & \multicolumn{3}{c|}{ Study period } \\
\hline & Baseline & Visit 2 & Visit 3 \\
\hline Time point & 0 & $\begin{array}{c}\text { 9 days } \pm \text { 4 days after } \\
\text { baseline }\end{array}$ & $\begin{array}{c}\text { 2 years ( } \pm \text { 2 months) } \\
\text { after visit 3 }\end{array}$ \\
\hline \hline Enrolment & & & \\
Eligibility screen & $\mathrm{X}$ & & \\
\cline { 2 - 4 } & & & \\
\hline
\end{tabular}


Table 1 continued

\begin{tabular}{|c|c|c|c|}
\hline Informed consent & $\mathrm{x}$ & & \\
\hline \multicolumn{4}{|l|}{ Randomization } \\
\hline Allocation & $\mathrm{x}$ & & \\
\hline \multicolumn{4}{|l|}{ Interventions } \\
\hline \multicolumn{4}{|l|}{ Alternate day fasting } \\
\hline \multicolumn{4}{|l|}{ Assessments } \\
\hline \multicolumn{4}{|l|}{ CRF } \\
\hline Demographic data & $\mathrm{x}$ & & $\mathrm{x}$ \\
\hline Anthropometric measurements & $\mathrm{X}$ & & $\mathrm{x}$ \\
\hline Vital signs (blood pressure, heart rate) & $\mathrm{x}$ & $\mathrm{x}$ & $\mathrm{x}$ \\
\hline Medical history & $\mathrm{x}$ & & $\mathrm{x}$ \\
\hline Concomitant medication & $\mathrm{x}$ & $\mathrm{x}$ & $\mathrm{x}$ \\
\hline Physical examination & $\mathrm{x}$ & & $\mathrm{x}$ \\
\hline \multicolumn{4}{|l|}{ Laboratory } \\
\hline Oral glucose tolerance test (OGTT) & $\mathrm{x}$ & $\mathrm{x}$ & $\mathrm{x}$ \\
\hline Saliva sampling & $\mathrm{x}$ & $\mathrm{x}$ & \\
\hline Urine pregnancy test (females) & $\mathrm{x}$ & $\mathrm{x}$ & \\
\hline Buccal mucosa sampling & & $\mathrm{x}$ & \\
\hline Laboratory measurements including routine & $\mathrm{x}$ & $\mathrm{x}$ & $\mathrm{x}$ \\
\hline Urine sampling & $\mathrm{x}$ & $\mathrm{x}$ & $\mathrm{x}$ \\
\hline Faeces sampling & $\mathrm{X}$ & & \\
\hline \multicolumn{4}{|l|}{ Issue of Devices } \\
\hline 24h ambulatory blood pressure monitoring & $\mathrm{x}$ & & \\
\hline Physical activity measurement & $\mathrm{X}$ & & \\
\hline Continuous glucose monitoring & $\mathrm{x}$ & & \\
\hline $\begin{array}{l}\text { Glucometer for calibration of glucose } \\
\text { monitoring }\end{array}$ & $\mathrm{x}$ & & \\
\hline \multicolumn{4}{|l|}{ Investigations } \\
\hline Endothelial function & & $\mathrm{x}$ & \\
\hline
\end{tabular}


Table 1 continued

\begin{tabular}{|c|c|c|}
\hline $\begin{array}{l}\text { Bone densitometry and body composition } \\
\text { (Dual-energy X-ray absorptiometry) }\end{array}$ & $\mathrm{x}$ & \\
\hline Hand grip test & $\mathrm{x}$ & \\
\hline Echocardiogram & $\mathrm{x}$ & \\
\hline Electrocardiogram (ECG) & $\mathrm{x}$ & \\
\hline Retina vessel analysis & $\mathrm{x}$ & \\
\hline Resting energy expenditure (REE) & $\mathrm{X}$ & \\
\hline Questionnaires & & \\
\hline Food frequency questionnaire (FFQ) & $\mathrm{X}$ & $\mathrm{x}$ \\
\hline $\begin{array}{l}\text { International physical activity questionnaire } \\
\text { (IPAQ) }\end{array}$ & $\mathrm{x}$ & $\mathrm{x}$ \\
\hline Health survey short form (SF36) & $\mathrm{x}$ & $x$ \\
\hline
\end{tabular}

randomized controlled study design or examined the effect of intermittent fasting alone in an uncontrolled way. The majority of these trials were performed in overweight subjects with or without type 2 diabetes mellitus.

Our trial is the first rigorously randomized controlled human study comparing metabolic and molecular effects of ADF with 100\% caloric restriction on the fast day to a control group with daily food intake over a period of 4 weeks in healthy subjects, controlled for study group adherence by continuous glucose monitoring. In addition, we will include a cohort of 30 subjects performing ADF for already more than 6 months.

The primary objective is to elucidate to which extent ADF influences human physiology in healthy individuals both short- and midto long term. The secondary objective of this study is to investigate novel molecular markers and cellular pathways of ageing and age-related diseases and whether they are influenced by ADF. The information gained through this project will be used to develop a strategy for follow-up studies in model organisms and humans. As a long-term goal, we want to identify new targets (metabolites, macromolecules and pathways) that can be used for more precise clinical diagnosis and in the treatment and prevention of ageing and age-related diseases.

The overarching aim of this research project is to elucidate whether and to what extent alternate day fasting influences physiology in healthy individuals in short- and mid- to longterm ADF. The secondary objective is to define novel molecular markers and cellular pathways of ageing and age-related diseases and whether they are influenced by ADF.

\section{METHODS}

\section{Study Design}

The InterFast trial is a cohort study with an integrated randomized controlled pilot trial. The aim of our cohort study with embedded pilot randomized control trial (RCT) is to investigate the effects of repeating fasting periods on human physiology, the ageing process and molecular cellular processes in humans. By performing this trial we are able to study midto long-term (subjects in the cohort study who had already practiced ADF for at least 6 months) and short-term effects (subjects randomized to ADF for 4 weeks or control group) of this 
nutritional intervention. All study participants in the RCT and cohort trial attend our study centre for a 2-year follow-up visit. In this study visit vital signs, anthropometric measures and blood samples are collected (see Table 1). Furthermore, patients are asked to answer questionnaires about nutritional behaviours and quality of life.

\section{Planned Outcomes}

The following outcome measures include both the cohort study and the RCT. In the cohort trial the group comparison will be performed at baseline, whereas in the embedded RCT, the changes over 4 weeks between the groups will be compared.

\section{Primary Outcome Measures (Differences Between Groups)}

- Differences in body composition (fat mass and lean body mass).

- Differences in resting energy expenditure.

- Differences in insulin sensitivity [Matsuda index, insulin sensitivity index (ISI), homeostatic model assessment of insulin resistance (HOMA-IR) index, quantitative insulin sensitivity check index (QUICKI)].

- Difference in glycaemic pattern (continuous glucose measurement).

- Differences in endothelial function (reactive hyperaemia index, stiffness index, aortic augmentation index).

- Differences in mean 24-h blood pressure.

- Differences in hormonal regulation (reproduction hormones, appetite hormones and others).

\section{Secondary Outcome Measures (Differences Between Groups)}

- Levels of various cell signalling and cell cycle proteins.

- Post-translational changes of signalling proteins.

- Differences in parameters of cell death (apoptosis, stress resistance, mitochondrial damage).
- Differences in various markers of ageing [telomere length, insulin growth factor-1 (IGF-1), etc.]

- Difference in epigenetic markers and metabolomics.

- Markers of inflammation and cardiovascular health.

- Differences in echocardiographic measures.

\section{Study Registration}

The study is performed according to the principles of the International Declaration of Helsinki and of good clinical practice (GCP), is approved by the ethics committee of the Medical University of Graz (27-166 ex 14/15) and is conducted at the Division of Endocrinology and Diabetology at the Medical University of Graz (academic hospital), Austria. The study is registered in the Database for Clinical Trials of the US National Institutes of Health (ClinicalTrials.gov Identifier: NCT02673515). Important protocol modifications will be reported to the local Ethics Committee of the Medical University of Graz. This study follows the international recommendations for interventional trials.

\section{Sample Selection}

The study population consists of 90 healthy subjects. Thirty participants already have practiced alternate day fasting for at least 6 months. Participants in the RCT are healthy subjects without recent AFD experience and are matched at least by sex and age. A separate informed consent was created for the interventional trial.

Due to the pilot nature of the study, no formal power calculation was performed.

\section{Recruitment}

Patients without previous ADF history who are assigned for the 4-week short-term fasting trial are identified via Primary Care and advertisements (Facebook, newspaper, trial-specific website). ADF subjects are recruited by advertisements and leaflets at Alternate Day Faster Events and online via different blogs. Subjects are recruited by the investigators and the study 
nurse in charge. Detailed information about the study background and protocol are given, and any potential questions brought forward by the subjects are answered before signing the informed consent. Each eligible subject who is willing to participate in the study signs a written informed consent before any particular study procedure.

\section{Randomization Procedures}

As part of the pilot RCT, the study participants without previous ADF history are randomly assigned to one of the two groups, ADF or control group, in a 1:1 ratio, using the webbased randomization tool "Randomizer for Clinical Trials" (www.randomizer.at), provided by the Institute of Medical Informatics, Statistics and Documentation of the Medical University Graz, Austria. The randomization is stratified by gender.

\section{Inclusion Criteria}

- Age between 35 and 65 years, both inclusive.

- Body mass index (BMI) between 22.0 and $30.0 \mathrm{~kg} / \mathrm{m}^{2}$, both inclusive.

- Fasting blood glucose $<110 \mathrm{mg} / \mathrm{dl}$ without glucose-lowering medication.

- LDL cholesterol $<180 \mathrm{mg} / \mathrm{dl}$ without lipidlowering medication.

- Blood pressure $<140 / 90 \mathrm{mmHg}$ without blood pressure-lowering medication.

- Stable weight (change $< \pm 10 \%$ ) for 3 months immediately prior to the study.

\section{Exclusion Criteria}

- History of metabolic disorder.

- History of cardiovascular disease.

- Acute or chronic inflammatory disorder.

- Known malignancy.

- Tobacco consumption within 5 years.

- Abuse of recreational drugs within 5 years.

- Alcohol abuse (more than 15 drinks/week).
- Dietary restrictions (e.g. vegetarianism and veganism).

- Women and men on hormonal supplementation.

- Women or men on hormone-based contraceptive agents within the past 2 months.

- Therapy with antidepressants within the past 6 months.

- Regular therapy with acetylsalicylic acid or current medication to regulate blood sugar, blood pressure or lipids.

- Women who are pregnant, breast-feeding or aiming to become pregnant during the course of the trial.

\section{Data Collection}

Once informed consent has been signed, physicians complete a paper-based case report form (CRF) for each participant to document socio-demographic information, anthropometric measurements, vital signs, information about medical history, concomitant medication, physical examination and dietary habits. Source documents comprise the CRF and hospital records as well as laboratory records. All documents are stored safely in a confidential manner. The subjects are referred to by a unique study subject number/code; their initials and date of birth will be reported on all studyspecific documentations. Personal identifiers are on the signed informed consent forms, subject identification log and subject clinical file, all of which will be stored securely by the clinical site. Source data are prepared accordingly for internal monitoring and possible external audits or inspections by regulatory authorities (Figs. 1, 2).

\section{Interventions}

ADF group: Subjects are asked to refrain from eating on the fast days and to eat ad libitum on the days between the fast days. On fasting days, subjects are only allowed to consume water, flavoured carbonated water, unsweetened tea or 


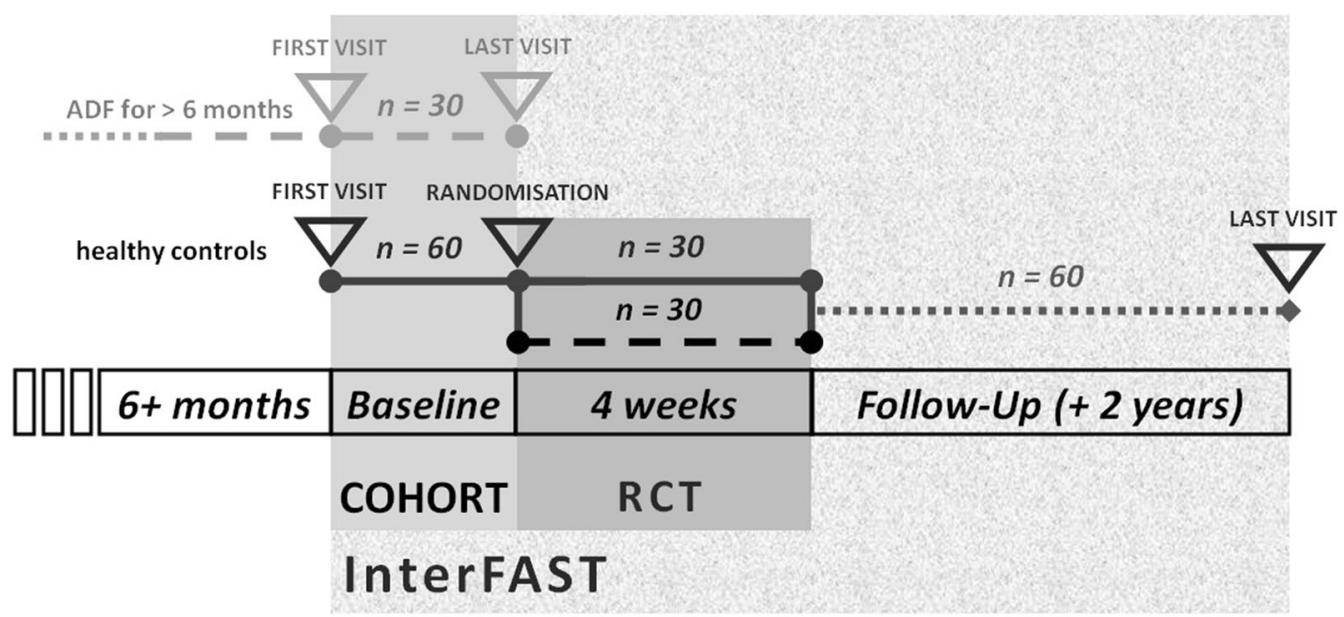

\section{- - - ADF Intervention Group \\ Controls \\ . . . . . . . . . RCT follow up without intervention}

Fig. 1 Study design

coffee. Furthermore, diet sodas or so called "calorie-free" meals or beverages are restricted.

\section{Measurements}

\section{Oral Glucose Tolerance Test (OGTT)}

Various insulin sensitivity indices derived from a frequently sampled, extended OGTT are calculated accounting for the various weighting of hepatic and peripheral insulin sensitivity expressed by the different indices. Insulin, C-peptide and glucose are measured before and $15,30,60$ and $120 \mathrm{~min}$ after a rapid ingestion of $75 \mathrm{~g}$ glucose, dissolved in $300 \mathrm{ml}$ of faucet water $\left({ }^{\circledR}\right.$ Glucoral 75 citron, Germania Pharmazeutika, Vienna). A standard gauge cannula is placed into a subcutaneous vein for blood sampling. To prevent blood clotting in the cannula and to keep it working, it is flushed with sterile normal saline after each blood drawing. The blood at each time point is placed into a fluoride oxalate tube $(1 \mathrm{ml})$ for plasma glucose and into a serum tube for analyses of insulin and c-peptide levels.

The insulin sensitivity index is calculated from the OGTT according to four different equations: the Matsuda index (IS OGTT $_{\text {): }}$ ISoGTT $=\frac{10000}{\sqrt{(\text { glucose } 0 * \text { insulin } 0) *(\text { mean }}} \quad$ glucose $*$ mean insulin) [36], the HOMA-IR: HOMA - IR = $\frac{\mathrm{FPG}(\mathrm{mmol} / \mathrm{l}) * \mathrm{FSI}(\mathrm{U} / \mathrm{l})}{22.5} \quad[37]$ and the QUICKI $=$ $\frac{1}{\log (\text { insulin } 0)+\log (\text { glucose } 0)}[38]$. The last equation was proposed by Stumvoll et al.: ISI $=0.222-0.00$ $333 * \mathrm{BMI}-0.0000779 *$ Ins $120-0.000422$ *age [39].

Beta cell function is estimated in the fasting state with HOMA - $\beta=\frac{20 * \text { Insulin } 0}{\text { Glucose } 0-3.5}$ [37] and during the OGTT with the Stumvoll index: 1 st phase $=1283+1.829 *$ Ins30 $-138.7 *$ Glc $30+3.772 *$ Ins 0 plus 2 nd phase $=286+0.416 *$ Ins $30-25.94 *$ Gluc $30+0.926 *$ Ins 0 [39] and the ratio of the incremental insulin to glucose response over the first $30 \mathrm{~min}$ during the OGTT $\Delta$ Insulin (30) $\Delta$ Glucose (30).

\section{Endothelial Function}

Endo-PAT 2000 (Itamar Medical Ltd., Caesarea, Israel) is used to measure endothelium-dependent vaso-reactivity [40]. In brief, before measurements, the subjects are in supine position 


\section{Enrollment}

\section{Inclusion criteria:}

- Aged between 35 and 65 years

- BMl between 22.0 and $30.0 \mathrm{~kg} / \mathrm{m}^{2}$

- Fasting blood glucose $<110 \mathrm{mg} / \mathrm{dl}$ without glucose lowering medication

- LDL-cholesterol $<180 \mathrm{mg} / \mathrm{dl}$ without lipid lowering medication

- Blood pressure $<140 / 90 \mathrm{mmHg}$ without blood pressure lowering medication

- Stable weight (change $< \pm 10 \%$ ) for 3 months immediately prior to the study

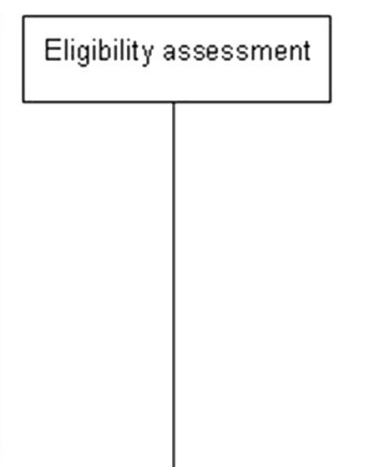
Exclusion criteria:
- History of metabolic disorders
- History of cardiovascular diseases
- Acute chronic inflammatory disorder
- Use of tobacco within 5 years
- Use of recreational drugs within 5 years
- Heavy drinking (>15 drinks/week)
- Vegetarianism or vegan nutrition
- Woman and men on hormonal supplementation

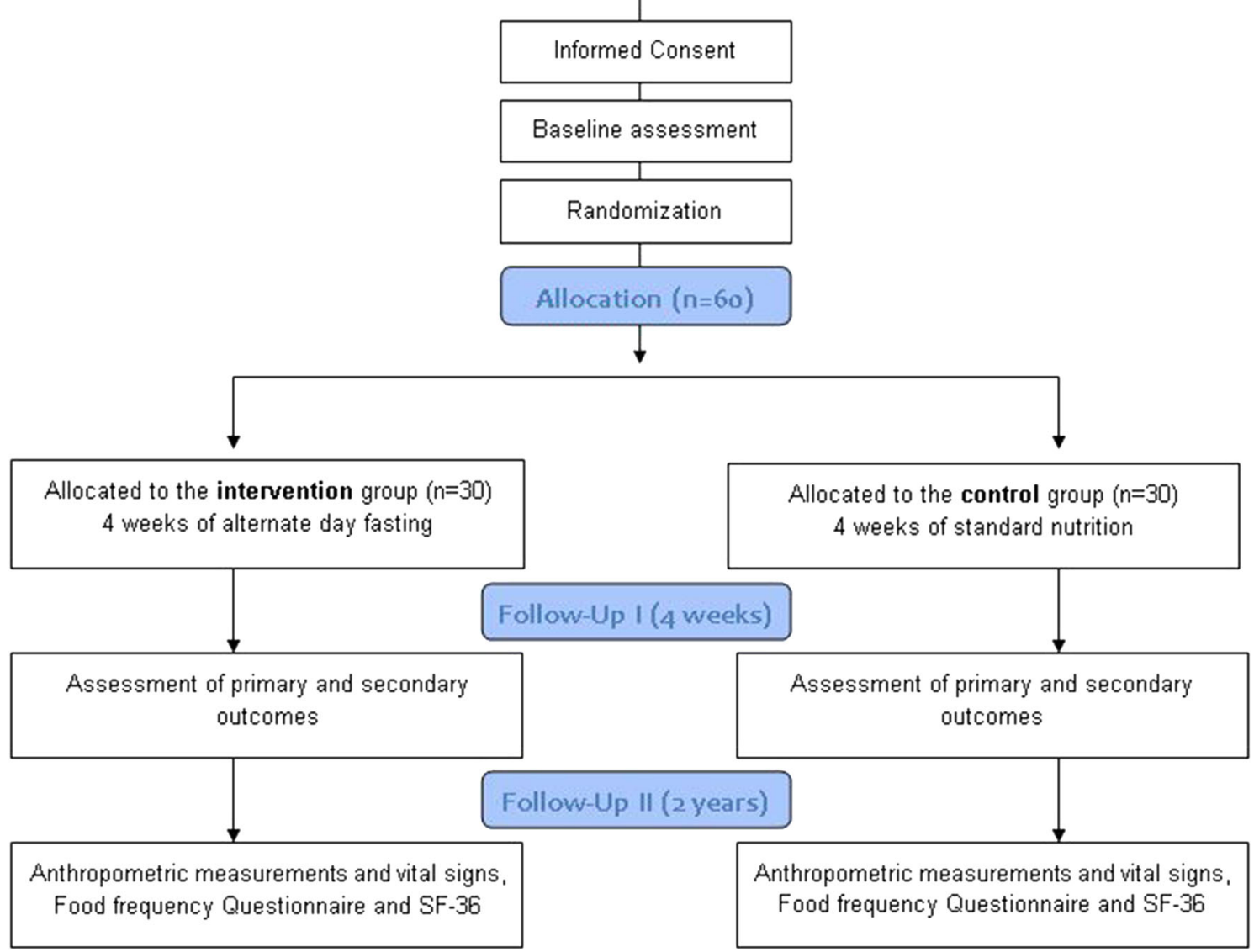

Fig. 2 Flow chart enrolment

for a minimum of $10 \mathrm{~min}$ in a quiet, temperature-controlled room with dimmed lights. Probes are placed on both index fingers and pulse wave amplitudes are detected and recorded during the investigation. After a 5-min baseline measurement, arterial flow is occluded using a cuff on the non-dominant arm. The cuff is inflated to $60 \mathrm{mmHg}$ above systolic pressure. After 5 min of occlusion, the cuff is rapidly deflated to allow reactive hyperaemia. Pulse 
wave amplitudes are recorded again for at least $5 \mathrm{~min}$ [41]. The ratio of the peripheral arterial tone (PAT) signal after cuff release compared with baseline is calculated through a computer algorithm automatically normalizing for baseline signal and indexed to the contralateral arm. The calculated ratio represents the reactive hyperaemia index (RHI) [42].

\section{Bone Densitometry and Body Composition}

Bone density scanning, also called dual-energy $\mathrm{X}$-ray absorptiometry (DXA) or bone densitometry, is an enhanced form of X-ray technology used to measure bone mass. Whole body DXA measurement is performed with a GE Lunar iDEXA (GE Healthcare, Waukesha, WI, USA) for the purpose of estimating body fat percentage according to the departmental standard operating procedure. Body regions are defined using standard anatomical partitions. Scan areas are analysed to determine lean mass, fat mass, bone mineral density and total body composition.

\section{Laboratory Measurements (Clinical and Hormonal)}

Insulin and c-peptide are measured by chemiluminescence on an ADVIA Centaur system (Siemens Healthcare Diagnostics, Eschborn, Germany). Hormones such as anti-muellerian hormone $(\mathrm{AMH})$, testosterone, cortisol, thyreotropin, triiodothyronine and thyroxine, oestrogen, sexual hormone-binding globulin (SHBG), luteotropic hormone ( $\mathrm{LH})$, follicle-stimulating hormone (FSH) and $25(\mathrm{OH})$ vitamin $\mathrm{D}$ are measured using automated analysers: $\mathrm{AMH}$ by Beckmann-Coulter, Krefeld, Germany; testosterone, cortisol, thyreotropin, triiodothyronine and thyroxine by Siemens ADVIA Centaur, Eschborn, Germany; SHBG by Roche Diagnostics, Mannheim, Germany; oestrogen, LH and FSH by Triturus, Biomedical Diagnostics, Antwerp, Belgium, 25(OH)vitamin D by iSYS, IDS, Boldon, UK, respectively. Samples for appetite hormones (leptin, ghrelin, PYY and others) are stored at $-80^{\circ} \mathrm{C}$ until analysis after centrifugation. Free fatty acids are measured enzymatically (Wako Chemical, Neuss, Germany) on an Olympus AU640 (Olympus Diagnostica, Hamburg, Germany). Routine parameters are determined using a $\operatorname{cobas}^{\circledR}$ analyser (Roche Diagnostics, Mannheim, Germany).

\section{Laboratory Measurements (Specialized Research-Ageing Parameters)}

Molecular parameters of ageing are determined by a variety of already established and previously described methods. Total levels as well as levels of phosphorylated proteins within different cell signalling pathways are measured using the Western blot system. Inflammatory markers, insulin signalling and precise characteristics of molecular pathways are analysed using certified and commercially available V-PLEX Assays (Meso Scale Discovery, Rockville, MD, USA). Epigenetic changes (methylation and acetylation) are analysed via traditional Western blotting using antibodies targeting post-translationally modified histones. All methods based on antigen-antibody interaction are followed using commercially available antibodies to assure better reproduction and optimal processes and procedures. Metabolomics, proteomics and acetylproteomics are measured using high-performance liquid chromatography (HPLC)-coupled mass spectrometry (MS) or HPLC-coupled MS/MS methods. Different parameters of cell death (apoptosis, stress resistance, mitochondrial damage) and age-related parameters are analysed using $\mathrm{BD}$ Bioscience LSRFortessa and FACSAria IIu flow cytometry systems.

\section{Physical Activity Measurement}

The MoviSens device consists of a $5.3 \times 3 \times 2 \mathrm{~cm}$-sized body and can be fixed with a clip to the hip area. During the measurements, the sensor is placed on the right side of the subjects' hip. The sensor is a three-axial acceleration sensor with a range of $\pm 8 \mathrm{~g}, 12$-bit resolution and $128-\mathrm{Hz}$ sampling rate. The recorded data from the sensor, including raw data from the acceleration sensor, can be displayed on a computer via USB cable. Energy expenditure is displayed in 1-s steps. Short time intervals allow monitoring spontaneous activities. The recognition of different activities is based on the extraction of mathematical and statistical 
features of the raw acceleration signal. The features are calculated for each 4-s segment. Calculated features are the maximum frequency, step count and number of mean crossings. These features are the input information of quantifying the activity of the subject. Activities that can be detected are rest (combination of lying, sitting and standing), bicycle or ergometer, going upstairs, walking (sensor-based differentiation of jogging, going downstairs, walking slowly, normally and fast) and undefined activity. The accuracy of the activity recognition algorithm is discussed by Jatobá et al. [43]. This device measures the physical activity of study participants over the 7-day period.

\section{Non-invasive 24-h Ambulatory Blood Pressure Monitoring}

Before measurement, arm circumference is measured to allow correct choice of cuff size. Subjects wear the blood pressure device for a single $24-\mathrm{h}$ period. During this time, the device is programmed to inflate and record blood pressure at pre-specified intervals (usually every 15 min during daytime hours and every $30 \mathrm{~min}$ during nighttime hours), which provides 50-75 approximately evaluable blood pressure recordings during the 24 -h period. Study participants are asked to keep an activity log throughout the 24-h period so activities can be connect onto the blood pressure recordings. The process for educating subjects about the blood pressure device and setting up the test takes approximately $10 \mathrm{~min}$. Patients should undergo testing on a regular workday [44]. The devices used are standardized brachial, oscillometric, automated Mobil-O-Graph ${ }^{\circledR}$ 24-h PWA (Stolberg, Germany) devices, which are used in the course of many studies.

\section{Resting Energy Expenditure (REE)}

REE is a component of energy expenditure measured by indirect calorimetry (IC). Subjects have to rest at least $30 \mathrm{~min}$ after not less than $8 \mathrm{~h}$ of sleep and after at least $3 \mathrm{~h}$ of fasting. During measurements, subjects must be kept fully awake and completely relaxed at normal breath. The measurements have to be carried out for at least $30 \mathrm{~min}$ and are performed at standard neutral hospital room temperature. A breath mask covers the subject's face. Oxygen consumption and carbon dioxide production will be measured and energy expenditure calculated by the Weir formula [45].

\section{Hand Grip Test}

One of the most common methods of measuring muscle strength is the isometric grip strength test. We will measure isometric grip strength using a handgrip dynamometer (JAMAR $^{\circledR}$, Nottinghamshire, UK). The test is performed in the sitting position with the upper arm of tested extremity adducted, the elbow flexed at $90^{\circ}$; the forearm and wrist are set in neutral position [46]. The testing protocol consists of three maximal isometric contractions for $5 \mathrm{~s}$ on both hands with a rest period of at least $60 \mathrm{~s}$. The mean value of the three contractions is used for determination of grip strength. The subjects are instructed to squeeze the dynamometer as hard as possible [47].

\section{Electrocardiogram (ECG)}

A 12-lead ECG is performed by the study nurse, who is familiar with the used ECG device (Mac 1200, Marquette Hellige GmbH, Freiburg, Germany). The ECG printout is interpreted, signed and dated by a co-investigator.

\section{Saliva Sampling}

Saliva is collected with Salitubes (DRG Instruments Marburg, Germany) using a routine method for saliva collection and dedicated tubes as well as standardized instructions for the collection. The hormones and salivary microbiome are analysed (adapted ELISAs by BSM, Vienna, Austria).

\section{Buccal Mucosa Sampling}

The study participants perform a mouth wash with distilled water (three replicates) to remove traces of saliva, contamination and surface mucous. Then exfoliation of the two cheeks to maximize the cell sample and remove any unknown trace that could be caused by sampling only one cheek is performed. The exfoliation should use a disposable brush similar to 
that used for a Papanicolaou smear, performing ten rotations of the brush against the inner wall of the cheeks starting in the centre and gradually increasing the circumference, producing a spiral effect to increase the sampling of a larger area and prevent erosion of a single region. After exfoliation, the brushhead must be placed in a container (test tube) with $0.4 \mathrm{ml}$ of buffer solution containing $0.01 \mathrm{M}$ Tris hydrochloride (Tris $\mathrm{HCl}$ ), $0.1 \mathrm{M}$ acid ethylenediaminetetraacetic (EDTA) and $0.02 \mathrm{M}$ sodium chloride $(\mathrm{NaCl})$ with $\mathrm{pH} 6.8$, turned in the way that the cells are released and displaced on the inner edge of the container [48].

The micronucleus (MN) assay in exfoliated buccal cells is a useful and minimally invasive method for monitoring genetic damage in humans [49]. The buccal micronucleus cytome (BMCyt) assay is a minimally invasive method for studying DNA damage, chromosomal instability, cell death and the regenerative potential of human buccal mucosal tissue. This method is increasingly used in molecular epidemiological studies for investigating the impact of nutrition, lifestyle factors, genotoxin exposure and genotype on DNA damage, chromosome malsegregation and cell death. The biomarkers measured in this assay have been associated with increased risk of accelerated ageing, cancer and neurodegenerative diseases [50].

\section{Blood Sampling and Storage}

Blood sampling is performed during the morning (7:00 a.m.-8:30 a.m.) after overnight fasting. Before blood sampling, subjects remain in the seated position for at least $10 \mathrm{~min}$.

Over the study in those participating in the cohort study, approximately $150 \mathrm{ml}$ of blood in total is taken to determine the parameters outlined above; in those also participating in the RCT (cohort study and RCT) overall approximately $200 \mathrm{ml}$ of blood is drawn. A potential remainder of serum and plasma is stored pseudonymised (patient number and visit number only) at $-80^{\circ} \mathrm{C}$ at the Biobank of the Medical University of Graz for potential future analyses. Therefore, subjects are asked to sign a separate informed consent for the Biobank.

\section{Faeces Sampling}

Faeces sampling is performed using stool collection tubes by Sarstedt, Nümbrecht, Germany, with a stool collector (Süsse Stuhlfänger, Gudensberg, Germany). One tube is used for native stool, the other prefilled with stool DNAstabilizer for collection of DNA-stabilized stool specimens. Directions for safe and hygienic faecal collection are delivered to the subjects, explaining in words as well as in pictograms. Bacterial DNA are extracted from saliva and stool samples using the MagNA Pure LC DNA Isolation Kit III (Roche). The 16S rRNA gene is amplified in a PCR reaction, sequenced with next-generation sequencing technology (Roche Genome Sequencer FLX or Illumina MiSeq) and interpreted by the respective software analysers.

\section{Continuous Glucose Monitoring (CGM)}

Minimally invasive CGM is performed using the Abbott FreeStyle Navigator II glucose-monitoring device (Abbott Diabetes care, Alameda, CA, USA) and the Medtronic Ipro2 (Minneapolis, USA). A sensor is introduced painlessly through the skin into the subcutaneous fat tissue. Then, a small transmitter is connected to the sensor. This construction is fixed to the skin with an adhesive tape for better adherence. The abdomen and upper arm are the two main body locations for applying the sensors, which are worn for 6-8 days by the study participants. Capillary blood sugar measurement performed with the commercially available Accu-Chek ${ }^{\circledR}$ Performa glucometer (Mannheim, Germany) is conducted to collect reference values for the required sensor calibration for the Medtronic System (at least all $12 \mathrm{~h}$ ). The Abbott sensor is factory calibrated and therefore does not require calibration by capillary prick blood. However subjects are instructed to scan the sensor with the corresponding recorder at least every $8 \mathrm{~h}$. Each scan displays a real-time glucose result, a historical trend and the direction the glucose is heading indicated by an arrow.

\section{Physical Examination}

Physical examination is done by the trial physician, who assesses the health status of each study participant (e.g. general appearance, 
neck/thyroid, chest/lung., etc.) and evaluates each section as normal/abnormal; if an abnormality is clinically significant he or she will define the findings in writing.

\section{Anthropometric Measurements}

Body weight is measured with the patient standing and then registered after rounding to the nearest $500 \mathrm{~g}$. Height is measured using a metric tape with the patient standing against the wall and the value marked by a ruler placed horizontally to the head of the patient. BMI is estimated using the weight in kilograms divided by the second power of the height expressed in meters.

Waist circumference is measured by the same study nurse in the morning in the fasting state. According to the World Health Organization (WHO) guidelines, waist circumference is measured at the midpoint between the top of the iliac crest (upper edge of the main pelvic bone) and lower margin of the last palpable rib in the mid axillary line (lowest point of the rib cage that can be located by touch along the side of the body). Hip circumference is measured in a similar manner, with the tape being passed around the hips at the widest circumference of the buttocks.

\section{Vital Signs}

Blood pressure is taken using an automated sphygmomanometer Boso Medicus Uno (Bosch \& Sohn GmbH, Juningen, Germany) after a 5-min rest. The blood pressure should be measured in a sitting position, with legs uncrossed, the back and arms in an upright position. Subjects should not talk during the measurement. Pulse as beats per minute is recorded after resting for $5 \mathrm{~min}$ in a sitting position by palpating the radial artery.

\section{Echocardiography}

Transthoracic echocardiography is performed with a Vivid E9 (GE Healthcare, Chalfont St Giles, UK) at the Department of Cardiology Medical University of Graz, Graz, Austria. Examinations are performed by investigators with vast experience in echocardiography (EK or NV) who are blinded to individual participant data, except name and birth date. Recorded images and loops are digitally saved for later analyses. All measurements are performed by a single investigator (NV) under blinded conditions, and AS serves as supervisor for data measurement. For acquisition of images in the parasternal view the participant is placed in the steep left-lateral decubitus position. The participant's left arm is raised above the head. Images are acquired during quiet respiration. The image rate is at least 30 frames per second. Target measurements include, among others, the left ventricular mass index, end-diastolic and end-systolic volume, left ventricular ejection fraction, parameters of left ventricular diastolic function and left atrial volume index. All data are assessed as recommended in international guidelines $[29,51]$.

\section{International Physical Activity Questionnaire (IPAQ)}

IPAQ is used in the current study. This tool was developed in 1998 for measuring physical activity and was followed by extensive reliability and validity testing undertaken across 12 countries (14 sites) during $2000[52,53]$. The final results suggested that this tool had acceptable measurement properties for use in many settings and in different languages and was suitable for national population-based prevalence studies of participation in physical activity. The short version of IPAQ tool is used in the current study. The tool includes a set of four questionnaires. The questions focus on the time spent being physically active in the last 7 days.

\section{SF 36 Health Questionnaire}

The short form 36 (SF 36) health questionnaire presents the short version of a battery of 149 health questions used in the RAND Corp. study of health insurance in the US [54]. The aspects of the questions regarding functional status, general wellbeing and overall evaluation of health can be completed in less than $10 \mathrm{~min}$ while retaining the validity and reliability of the longer questionnaire [55]. Because the study is performed in Austria, the German version of the questionnaire is used. 


\section{Food Frequency Questionnaire (FFQ)}

A self-administered, semi-quantitative FFQ was developed to assess usual food consumption within the German Health Examination Survey for Adults 2008-2011 (DEGS) [56]. The relative validity of this questionnaire was studied among participants of another nationwide survey, the German National Nutrition Monitoring (NEMONIT) [57]. The FFQ includes questions about the frequency and amount of 53 food items consumed during the past 4 weeks. Frequency of consumption of food behaviours is requested according to specified categories. In addition, the respondents have to indicate the portion size of the food items consumed in predefined answering categories. Pictures are used to aid the estimation of portion size for 33 food items. In total, 29 food groups are presented by the food frequency questionnaire. Because the study is performed in Austria, the German version of the questionnaire is used.

\section{Data Analysis}

Statistical analyses for primary and secondary outcomes as well as for baseline values are done in a descriptive and exploratory way. Primary outcomes are defined by various parameters, whereas each primary outcome has to be operationalized for the statistical analysis to investigate the influence of $\mathrm{ADF}$, as the physiological changes are represented in various parameters.

Insulin sensitivity is here stated as a representative example. Insulin sensitivity is calculated according to four different equations (detailed information in the methods section) that are influenced by BMI and age, amongst others. Insulin sensitivity is also related to physical activity. The physiological relations are very complex. To understand various effects and multiple relations statistical multivariate models are built to have comprehensible scenarios: GLMs (generalized linear mixed models) with age, BMI and physical activity as additional variables with interactions are used to see significant and main covariates.

Further, for exploratory analysis continuous variables are summarized with standard descriptive statistics tables and represented graphically with displays such as box plots and histograms, and categorical variables are described by frequency tables and standard graphical displays such as bar plots. Scatterplots are used to illustrate possible correlations between the variables. Student's $t$ tests or Mann-Whitney $U$ tests and chi square tests are used as appropriate. Comparisons within groups are performed using a paired $t$ test or Wilcoxon rank-sum test. $p<0.05$ is considered to indicate statistical significance, whereas appropriate correction for multiple testing such as the Bonferroni correction or false discovery rate (Benjamini and Hochberg) is applied. For high-dimensional "omics" data appropriate multivariate modelling such as random forests and partial least squares regression are used to elucidate differences between groups concerning potential molecular markers regarding ageing effects. If necessary, a statistical analysis plan is prepared in addition to the study protocol. Statistical software R [58] and SAS v.9.4 are used for statistical analysis.

\section{STRENGTHS AND LIMITATIONS OF THIS STUDY}

- This is the first prospective cohort study with an embedded randomized intervention trial that will be conducted to investigate shortand mid- to long-term effects of ADF on human physiology and molecular cellular processes in healthy subjects.

- The methods for analysis of the outcomes are precise and reliable.

- Glucose levels are assessed using CGM.

- In our study, subjects are only allowed to consume water, flavoured carbonated water, tea or sugarless coffee on their fast days (complete caloric restriction) compared with previous trials (partially reduction of daily calorie intake).

- Besides routine laboratory, hormonal and molecular measurements, we collect many clinical data and biological biobank material and perform a large set of investigations including calorimetry, endothelial function measurement and echocardiography, which will allow us look into the mechanisms of $\mathrm{ADF}$ and to generate hypothesis. 


\section{ETHICS AND DISSEMINATION}

\section{Ethics Approval and Consent \\ to Participate}

The study is performed according to the principles of the International Declaration of Helsinki and to the principles of good clinical practice (GCP) and was approved by the ethics committee of the Medical University of Graz (27-166 ex 14/15) on 27 February 2016. The trial is conducted at the Division of Endocrinology and Diabetology at the Medical University of Graz (academic hospital), Austria. The protocol is registered in ClinicalTrials.gov using the following identifier: NCT02673515.

Important protocol modifications are reported to the local ethics committee of the Medical University of Graz.

Participants are asked to sign informed consent before being enrolled into the trial, in compliance with the Declaration of Helsinki and the WHO standards. Subjects are informed of the study objectives and the risks and benefits of the examinations they will undergo. All subjects are given enough time to decide whether they wish to participate in the trial.

The trial includes collection of biological samples (blood, urine, stool, sputum), of which subjects are informed carefully. The samples are stored at $-80^{\circ} \mathrm{C}$ for use in future research at the Biobank of the Medical University of Graz.

\section{Dissemination Plan}

We anticipate that the results of this study will be disseminated through peer-reviewed journals and national and international academic conferences. Additionally, all trial participants will be invited to an informational event, in which study results will be presented by the study team.

\section{DISCUSSION}

Clinical research studies of ADF with robust designs and high levels of clinical evidence are sparse. The primary aim of this trial is to elucidate whether and to what extent alternate day fasting influences human physiology in healthy individuals in both short- and mid- to longterm investigations. Besides routine laboratory, hormonal and molecular measurements, we collect many clinical data as well as biological biobank material and perform a large set of investigations including calorimetry, endothelial function measurement and echocardiography, which will allow us look into mechanisms of ADF and generate hypotheses that can be further tested in larger clinical trials.

\section{Trial Status}

The first patient was included on 8 April 2015. The study is ongoing; close out is scheduled for April 2019. Participants are no longer being recruited.

\section{ACKNOWLEDGEMENTS}

We are very grateful to our study participants for their cooperation.

Funding. The study is funded by the AustrianScience Fund FWF (Austria) for grants P29262-B28, P29203-B27 and P27893-B28 (Frank Madeo). Frank Madeo acknowledges support from NAWI Graz and the BioTechMedGraz flagship project "EPIAge". No funding or sponsorship was received for the publication of this article.

Authorship. All named authors meet the International Committee of Medical Journal Editors (ICMJE) criteria for authorship for this article, take responsibility for the integrity of the work as a whole and have given their approval for this version to be published.

Authorship Contributions. Harald Sourij, Norbert J. Tripolt, Slaven Stekovic, Sabrina Schröder, Frank Madeo, Barbara Obermayer-Pietsch, Thomas R. Pieber designed the study protocol; Jasmin Url, Peter N. Pferschy and Felix Aberer have made substantial contribution to acquisition of data. Norbert J. Tripolt and Harald Sourij wrote the clinical protocol and obtained authorization from the Ethics 
Committee and wrote the manuscript. Albrecht Schmidt, Ewald Kolesnik, Nicolas Verheyen performed and evaluated the echocardiographic examinations. Sophie H. Narath and Regina Riedl are responsible for statistical analyses. Harald Sourij is the principal investigator of the trial. Thomas R. Pieber and Frank Madeo are the chief investigators of this trial. All authors read and approved the final manuscript.

Disclosures. Norbert J. Tripolt, Slaven Stekovic, Felix Aberer, Jasmin Url, Peter N. Pferschy, Sabrina Schröder, Nicolas Verheyen, Albrecht Schmidt, Ewald Kolesnik, Sophie H. Narath, Regina Riedl, Barbara Obermayer-Pietsch, Thomas R. Pieber, Frank Madeo and Harald Sourij have nothing to disclose.

Compliance with Ethics Guidelines. The trial is conducted in accordance with the ethical principles of the Declaration of Helsinki, International Council for Harmonisation Good Clinical Practice (GCP) and the applicable country-specific regulatory requirements. Informed consent was obtained from all individual participants included in the study.

Open Access. This article is distributed under the terms of the Creative Commons Attribution-NonCommercial 4.0 International License (http://creativecommons.org/licenses/ by-nc/4.0/), which permits any noncommercial use, distribution, and reproduction in any medium, provided you give appropriate credit to the original author(s) and the source, provide a link to the Creative Commons license, and indicate if changes were made.

\section{REFERENCES}

1. Faris MA, Kacimi S, Al-Kurd RA, Fararjeh MA, Bustanji YK, Mohammad MK, et al. Intermittent fasting during Ramadan attenuates proinflammatory cytokines and immune cells in healthy subjects. Nutr Res. 2012;32(12):947-55.

2. Joslin PM, Bell RK, Swoap SJ. Obese mice on a highfat alternate-day fasting regimen lose weight and improve glucose tolerance. J Anim Physiol Anim Nutr (Berl). 2017;101(5):1036-1045.
3. Catenacci VA, Pan Z, Ostendorf D, Brannon S, Gozansky WS, Mattson MP, et al. A randomized pilot study comparing zero-calorie alternate-day fasting to daily caloric restriction in adults with obesity. Obesity (Silver Spring). 2016;24(9):1874-83.

4. Varady KA, Bhutani S, Klempel MC, Kroeger CM, Trepanowski JF, Haus JM, et al. Alternate day fasting for weight loss in normal weight and overweight subjects: a randomized controlled trial. Nutr J. 2013;12(1):146.

5. Varady KA, Hoddy KK, Kroeger CM, Trepanowski JF, Klempel MC, Barnosky A, et al. Determinants of weight loss success with alternate day fasting. Obes Res Clin Pract. 2016;10(4):476-80.

6. Pedersen CR, Hagemann I, Bock T, Buschard K. Intermittent feeding and fasting reduces diabetes incidence in $\mathrm{BB}$ rats. Autoimmunity. 1999;30(4):243-50.

7. Anson RM, Guo Z, de Cabo R, Iyun T, Rios M, Hagepanos A, et al. Intermittent fasting dissociates beneficial effects of dietary restriction on glucose metabolism and neuronal resistance to injury from calorie intake. Proc Natl Acad Sci USA. 2003;100(10):6216-20.

8. Wan R, Camandola S, Mattson MP. Intermittent fasting and dietary supplementation with 2-deoxyD-glucose improve functional and metabolic cardiovascular risk factors in rats. FASEB J. 2003;17(9):1133-4.

9. Mager DE, Wan R, Brown M, Cheng A, Wareski P, Abernethy DR, et al. Caloric restriction and intermittent fasting alter spectral measures of heart rate and blood pressure variability in rats. FASEB J. 2006;20(6):631-7.

10. Krizova E, Simek V. Influence of intermittent fasting and high-fat diet on morphological changes of the digestive system and on changes of lipid metabolism in the laboratory mouse. Physiol Res Acad Sci Bohemosl. 1996;45(2):145-51.

11. Hatori M, Vollmers C, Zarrinpar A, DiTacchio L, Bushong EA, Gill S, et al. Time-restricted feeding without reducing caloric intake prevents metabolic diseases in mice fed a high-fat diet. Cell Metab. 2012;15(6):848-60.

12. Duan W, Lee J, Guo Z, Mattson MP. Dietary restriction stimulates BDNF production in the brain and thereby protects neurons against excitotoxic injury. J Mol Neurosci MN. 2001;16(1):1-12.

13. Duan W, Mattson MP. Dietary restriction and 2-deoxyglucose administration improve behavioral outcome and reduce degeneration of dopaminergic 
neurons in models of Parkinson's disease. J Neurosci Res. 1999;57(2):195-206.

14. Yu ZF, Mattson MP. Dietary restriction and 2-deoxyglucose administration reduce focal ischemic brain damage and improve behavioral outcome: evidence for a preconditioning mechanism. J Neurosci Res. 1999;57(6):830-9.

15. Carlson AJ, Hoelzel F. Apparent prolongation of the life span of rats by intermittent fasting. J Nutr. 1946;31:363-75.

16. Goodrick CL, Ingram DK, Reynolds MA, Freeman JR, Cider N. Effects of intermittent feeding upon body weight and lifespan in inbred mice: interaction of genotype and age. Mech Ageing Dev. 1990;55(1):69-87.

17. Johnson JB, Laub DR, John S. The effect on health of alternate day calorie restriction: eating less and more than needed on alternate days prolongs life. Med Hypotheses. 2006;67(2):209-11.

18. Varady KA, Dam VT, Klempel MC, Horne M, Cruz $\mathrm{R}$, Kroeger CM, et al. Effects of weight loss via high fat vs. low fat alternate day fasting diets on free fatty acid profiles. Sci Rep. 2015;5:7561.

19. Teng NI, Shahar S, Manaf ZA, Das SK, Taha CS, Ngah WZ. Efficacy of fasting calorie restriction on quality of life among aging men. Physiol Behav. 2011;104(5):1059-64.

20. Klempel MC, Kroeger CM, Varady KA. Alternate day fasting (ADF) with a high-fat diet produces similar weight loss and cardio-protection as ADF with a low-fat diet. Metab Clin Exp. 2013;62(1):137-43.

21. Bhutani S, Klempel MC, Kroeger CM, Trepanowski JF, Varady KA. Alternate day fasting and endurance exercise combine to reduce body weight and favorably alter plasma lipids in obese humans. Obesity. 2013;21(7):1370-9.

22. Belza A, Toubro S, Stender S, Astrup A. Effect of dietinduced energy deficit and body fat reduction on high-sensitive CRP and other inflammatory markers in obese subjects. Int J Obes. 2009;33(4):456-64.

23. Eshghinia S, Mohammadzadeh F. The effects of modified alternate-day fasting diet on weight loss and CAD risk factors in overweight and obese women. J Diabet Metab Disord. 2013;12(1):4.

24. Kroeger CM, Klempel MC, Bhutani S, Trepanowski JF, Tangney CC, Varady KA. Improvement in coronary heart disease risk factors during an intermittent fasting/calorie restriction regimen: relationship to adipokine modulations. Nutr Metab. 2012;9(1):98.
25. Heilbronn LK, Smith SR, Martin CK, Anton SD, Ravussin E. Alternate-day fasting in nonobese subjects: effects on body weight, body composition, and energy metabolism. Am J Clin Nutr. 2005;81(1):69-73.

26. Harvie MN, Pegington M, Mattson MP, Frystyk J, Dillon B, Evans G, et al. The effects of intermittent or continuous energy restriction on weight loss and metabolic disease risk markers: a randomized trial in young overweight women. Int $\mathrm{J}$ Obes. 2011;35(5):714-27.

27. Harvie M, Wright C, Pegington M, McMullan D, Mitchell E, Martin B, et al. The effect of intermittent energy and carbohydrate restriction $\mathrm{v}$. daily energy restriction on weight loss and metabolic disease risk markers in overweight women. $\mathrm{Br} \mathrm{J}$ Nutr. 2013;110(8):1534-47.

28. Johnson JB, Summer W, Cutler RG, Martin B, Hyun $\mathrm{DH}$, Dixit VD, et al. Alternate day calorie restriction improves clinical findings and reduces markers of oxidative stress and inflammation in overweight adults with moderate asthma. Free Radic Biol Med. 2007;42(5):665-74.

29. Lang RM, Bierig M, Devereux RB, Flachskampf FA, Foster E, Pellikka PA, et al. Recommendations for chamber quantification. Eur J Echocardiogr. 2006;7(2):79-108.

30. Varady KA, Bhutani S, Church EC, Klempel MC. Short-term modified alternate-day fasting: a novel dietary strategy for weight loss and cardioprotection in obese adults. Am J Clin Nutr. 2009;90(5):1138-43.

31. Horne BD, Muhlestein JB, Lappe DL, May HT, Carlquist JF, Galenko O, et al. Randomized cross-over trial of short-term water-only fasting: metabolic and cardiovascular consequences. Nutr Metab Cardiovasc Dis. 2013;23(11):1050-7.

32. Klempel MC, Kroeger CM, Varady KA. Alternate day fasting increases LDL particle size independently of dietary fat content in obese humans. Eur J Clin Nutr. 2013;67(7):783-5.

33. Varady KA, Bhutani S, Klempel MC, Lamarche B. Improvements in LDL particle size and distribution by short-term alternate day modified fasting in obese adults. Br J Nutr. 2011;105(4):580-3.

34. Halberg N, Henriksen M, Soderhamn N, Stallknecht B, Ploug T, Schjerling P, et al. Effect of intermittent fasting and refeeding on insulin action in healthy men. J Appl Physiol (1985). 2005;99(6):2128-36.

35. Seimon RV, Roekenes JA, Zibellini J, Zhu B, Gibson AA, Hills AP, et al. Do intermittent diets provide physiological benefits over continuous diets for 
weight loss? A systematic review of clinical trials. Amsterdam: Molecular and Cellular Endocrinology; 2015.

36. Matsuda M, DeFronzo RA. Insulin sensitivity indices obtained from oral glucose tolerance testing: comparison with the euglycemic insulin clamp. Diabetes Care. 1999;22(9):1462-70.

37. Matthews DR, Hosker JP, Rudenski AS, Naylor BA, Treacher DF, Turner RC. Homeostasis model assessment: insulin resistance and beta-cell function from fasting plasma glucose and insulin concentrations in man. Diabetologia. 1985;28(7):412-9.

38. Katz A, Nambi SS, Mather K, Baron AD, Follmann DA, Sullivan G, et al. Quantitative insulin sensitivity check index: a simple, accurate method for assessing insulin sensitivity in humans. J Clin Endocrinol Metab. 2000;85(7):2402-10.

39. Stumvoll M, Van Haeften T, Fritsche A, Gerich J. Oral glucose tolerance test indexes for insulin sensitivity and secretion based on various availabilities of sampling times. Diabetes Care. 2001;24(4):796-7.

40. Bonetti PO, Pumper GM, Higano ST, Holmes DR Jr, Kuvin JT, Lerman A. Noninvasive identification of patients with early coronary atherosclerosis by assessment of digital reactive hyperemia. J Am Coll Cardiol. 2004;44(11):2137-41.

41. Korhonen P, Syvanen K, Aarnio P. Surrogates of large artery versus small artery stiffness and anklebrachial index. Int J Angiol. 2011;20(3):167-72.

42. Bonetti PO, Lerman LO, Lerman A. Endothelial dysfunction: a marker of atherosclerotic risk. Arterioscler Thromb Vasc Biol. 2003;23(2):168-75.

43. Jatoba LC, Grossmann U, Kunze C, Ottenbacher J, Stork W. Context-aware mobile health monitoring: evaluation of different pattern recognition methods for classification of physical activity. In: Conference proceedings: annual international conference of the IEEE engineering in medicine and biology society IEEE engineering in medicine and biology society conference, 2008;2008:5250-3

44. Ernst ME, Bergus GR. Noninvasive 24-hour ambulatory blood pressure monitoring: overview of technology and clinical applications. Pharmacotherapy. 2002;22(5):597-612.

45. Weir JB. New methods for calculating metabolic rate with special reference to protein metabolism. J Physiol. 1949;109(1-2):1-9.

46. Mathiowetz V, Weber K, Volland G, Kashman N. Reliability and validity of grip and pinch strength evaluations. J Hand Surg. 1984;9(2):222-6.
47. White C, Dixon K, Samuel D, Stokes M. Handgrip and quadriceps muscle endurance testing in young adults. Springerplus. 2013;2:451.

48. Meneguetti DU, da Silva AF, Bosso R, Zan R, Ramos L. New method for detection of mutagenicity in oral mucosa the through of micronucleus test. HOAJ Biol. 2012;1:8.

49. Holland N, Bolognesi C, Kirsch-Volders M, Bonassi $\mathrm{S}$, Zeiger E, Knasmueller S, et al. The micronucleus assay in human buccal cells as a tool for biomonitoring DNA damage: the HUMN project perspective on current status and knowledge gaps. Mutat Res. 2008;659(1-2):93-108.

50. Thomas P, Holland N, Bolognesi C, Kirsch-Volders $\mathrm{M}$, Bonassi S, Zeiger E, et al. Buccal micronucleus cytome assay. Nat Protoc. 2009;4(6):825-37.

51. Nagueh SF, Smiseth OA, Appleton CP, Byrd BF 3rd, Dokainish H, Edvardsen T, et al. Recommendations for the evaluation of left ventricular diastolic function by echocardiography: an update from the american society of echocardiography and the European Association of Cardiovascular Imaging. Eur Heart J Cardiovasc Imaging. 2016;17(12):1321-60.

52. Ainsworth BE, Bassett DR Jr, Strath SJ, Swartz AM, O'Brien WL, Thompson RW, et al. Comparison of three methods for measuring the time spent in physical activity. Med Sci Sports Exerc. 2000;32(9 Suppl):S457-64.

53. Craig CL, Marshall AL, Sjostrom M, Bauman AE, Booth ML, Ainsworth BE, et al. International physical activity questionnaire: 12-country reliability and validity. Med Sci Sports Exerc. 2003;35(8):1381-95.

54. Ruta DA, Hurst NP, Kind P, Hunter M, Stubbings A. Measuring health status in British patients with rheumatoid arthritis: reliability, validity and responsiveness of the short form 36-item health survey (SF-36). Br J Rheumatol. 1998;37(4):425-36.

55. Ruta D, Garratt A, Abdalla M, Buckingham K, Russell I. The SF 36 health survey questionnaire. A valid measure of health status. BMJ. 1993;307(6901):448-9.

56. Robert-Koch-Institut. DEGS - Studie zur Gesundheit Erwachsener in Deutschland. Berlin: Robert Koch Institut; 2009.

57. Haftenberger M, Heuer T, Heidemann C, Kube F, Krems C, Mensink GB. Relative validation of a food frequency questionnaire for national health and nutrition monitoring. Nutr J. 2010;9:36.

58. R Foundation for Statistical Computing. R: a language and environment for statistical computing. Vienna: R Foundation for Statistical Computing; 2015. 